\title{
Avaliação do nível de satisfação dos usuários do serviço público de saúde: o caso de um centro de saúde na microrregião de Cajazeiras-
} PB

A reforma administrativa inseriu o modelo gerencialista na Administração Pública, buscando dá eficiência aos serviços públicos, para tanto trouxe conceitos, práticas e inovações do setor privado para o público, focalizando os serviços públicos nos principais alvos: o cidadão-usuário. No caso da saúde, os serviços são realizados por políticas sociais e econômicas por meio do Sistema Único de Saúde (SUS), que busca a melhoria da qualidade de vida da sociedade e focaliza suas ações na universalidade do atendimento aos usuários-cidadãos. Desta forma, objetivou-se com esse estudo, avaliar o nível de satisfação do usuário do serviço público de saúde prestado por um centro de saúde que integraliza a rede do SUS na Microrregião de Cajazeiras. A pesquisa está caracterizada como uma pesquisa qualitativa, com fins descritivos, exploratório, estudo de campo e de caso. Utilizou-se da pesquisa survey na aplicação do questionário como instrumento de coleta de dados. Os sujeitos da pesquisa foram os usuários do centro de saúde, cuja amostra foi caracterizada como não probabilística e por conveniência. Entendendo, ao final, que a satisfação dos usuários corrobora a literatura, a qual entende estar a satisfação diretamente ligada às expectativas criadas pelos usuários, sendo que o grau de satisfação dependerá de como as expectativas foram atendidas, e no caso in loco não difere.

\section{Evaluation of the satisfaction level of users of the public health service: the case of a health center in the microregion of Cajazeiras-}

PB

\begin{abstract}
The administrative reform inserted the managerial model in the Public Administration, seeking to give efficiency to public services, for it brought concepts, practices and innovations from the private sector to the public, focusing public services on the main targets: citizen-user. In the case of health, services are carried out through social and economic policies through the Unified Health System (SUS), which seeks to improve the quality of life of society and focuses its actions on the universality of care for the citizen users. In this way, the objective of the article is to evaluate the level of satisfaction of the public health service user provided by a health center that integrates the SUS network in the Cajazeiras Microregion. The research is characterized as a quantitative-qualitative research, with descriptive, exploratory, field and case study. The survey was used in the application of the questionnaire as a data collection instrument. The subjects of the research were the users of the health center, whose sample was characterized as non-probabilistic and for convenience. Understanding, in the end, that user satisfaction corroborates the literature, which understands that satisfaction is directly linked to the expectations created by users, and the degree of satisfaction will depend on how expectations were met, and in the case in loco does not differ.
\end{abstract}

Keywords: Level of satisfaction; User; Public Health Services; Microregion of Cajazeiras.

Topic: Políticas, Planejamento e Gestão de Sistemas e Serviços de Saúde

Reviewed anonymously in the process of blind peer.

Lucas Andrade de Morais

Universidade do Estado do Rio Grande do Norte, Brasil

http://lattes.cnpq.br/4304836710800316

http://orcid.org/0000-0003-4443-2393

lucasmorais7@gmail.com

Jamilton Costa Pereira (ii)

Universidade Federal de Campina Grande, Brasil

http://lattes.cnpq.br/2510943588040234

http://orcid.org/0000-0002-4724-7655

jcp_jamiltoncosta@hotmail.com

Gildevânia de Souza Lins Andrade

Universidade Federal de Campina Grande, Brasil

http://lattes.cnpq.br/0351608176380776

gildevania@hotmail.com

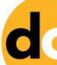

DOI: 10.6008/CBPC2236-9600.2021.003.0020
Received: 29/08/2021

Approved: 25/09/2021

\author{
Luan Caio Andrade de Morais \\ Universidade Federal de Campina Grande, Brasil \\ http://lattes.cnpq.br/1630928802623185 \\ http://orcid.org/0000-0002-4591-7854 \\ luancaio 7@hotmail.com \\ Cinthia Moura Frade \\ Universidade Estadual da Paraíba, Brasil \\ http://lattes.cnpq.br/5264348035661218 \\ http://orcid.org/0000-0002-2826-816X \\ admcinthiafrade@gmail.com
}

Referencing this:

MORAIS, L. A.; PEREIRA, J. C.; ANDRADE, G. S. L.; MORAIS, L. C. A.; FRADE, C. M.. Avaliação do nível de satisfação dos usuários do serviço público de saúde: o caso de um centro de saúde na microrregião de Cajazeiras-PB. Scire Salutis, v.11, n.3, p.154-164, 2021. DOI: http://doi.org/10.6008/CBPC2236-9600.2021.003.0020 


\section{INTRODUÇÃO}

O direito à saúde é garantido mediante políticas sociais e econômicas que visem à redução do risco de doenças e ao acesso universal e igualitário das ações e serviços para promoção, proteção e recuperação dos cidadãos. A saúde, enquanto direito social, está prevista no art. 6o da Constituição Federal de 1988 (CF/88), e como tal é incumbido ao poder público dispor, nos termos da lei, sobre sua regulamentação, fiscalização e controle, cuja execução poderá ocorrer diretamente pelos entes públicos ou por terceiros (ainda que sejam pessoas físicas ou jurídicas de direito privado).

A saúde passou a ser tratada como um direito social fundamental após a Constituição Federal de 1988, fruto das décadas de luta e movimento em prol da saúde pública, especialmente o "Movimento Sanitário", organizado por médicos e lideranças populares e a 8a Conferência Nacional de Saúde (1986) a qual serviu de base para a formação do Sistema Único de Saúde (SUS) e constituição do Conselho Nacional de Saúde (CNS) como órgão com poder de decisão, composto pelos trabalhadores da saúde, os gestores e os usuários (representantes da população em geral).

Embora previsto na CF/88, o SUS só foi regulamentado em 19 de setembro de 1990, pela Lei oㅡ 8.080, que reafirma a previsão constitucional no sentido explicitar a responsabilidade do Estado em garantir serviços de saúde aos cidadãos, exercido em cada esfera do poder. Portanto, a prestação dos serviços de saúde pelo SUS no que se refere ao âmbito municipal, tem sua gestão exercida pela Secretaria Municipal de Saúde (SMS) e se compõe de diversos programas, ações e estratégias que envolvem a promoção da saúde, tais como as Estratégias em Saúde da Família (ESF), Núcleo de Apoio a Saúde da Família (NASF), Serviço Ambulatorial Móvel de Urgência e Emergência (SAMU), ambulatórios, leitos de internações, dentre outros serviços de saúde prestados.

Frente ao exposto, o presente trabalho pretende desenvolver uma discussão em torno dos serviços prestados por um Centro de Saúde na Microrregião de Cajazeiras, município localizado na Paraíba, tendo como objetivo avaliar o nível de satisfação do usuário do serviço público de saúde. Para atingir esse objetivo, fez-se necessário descrever a estrutura da Administração Pública brasileira, enfocando-se o serviço público municipal em saúde e relacionando-se os fatores que levam à satisfação do usuário aos serviços prestados pelo órgão objeto de estudo, e ao final avaliar o nível de satisfação desses usuários, através da aferição dos questionários.

Esse estudo abordou sobre o nível de satisfação dos usuários, e para tanto foi aplicado um questionário durante um dia do expediente no Centro de Saúde. Desta forma, a atual pesquisa tem um caráter mais cientifico que buscou confirmar (ou não) os argumentos positivos e negativos que nós como usuários e pesquisadores haviam construído anteriormente sobre SUS e os serviços prestados em saúde. A escolha do Centro de Saúde se deu primeiramente por ele fazer parte da rede do SUS, bem como se tratar de centro de referência nas prestações dos serviços em saúde; em segundo lugar, devido ao grande número de usuários já que o ele além de atender usuários que residem no próprio município têm atendido também as cidades circunvizinhas, inclusive alguns municípios do Rio Grande do Norte-RN.

Para tanto, o trabalho foi estruturado, inicialmente, por uma fundamentação teórica, na qual foi 
abordada a estrutura da Administração Pública brasileira, enfocando-se o SUS e os serviços públicos municipal em saúde e fazendo um liame com a satisfação dos usuários. Posteriormente, foi apresentada a metodologia adotada para o estudo, seguida dos resultados obtidos por meio da análise dos questionários aplicados, quando se buscou responder as indagações feitas durante todo o trabalho e, por fim, foram expostas as conclusões da pesquisa.

\section{REVISÃO TEÓRICA}

A CF/88 dispõe a saúde como um direito social fundamental previsto nos artigos 6ㅇ, 196 e 197, estabelecendo como dever da Administração Pública garantir políticas para o acesso ao direito à saúde, bem como dispor, por meio da atividade legiferante, sobre sua regulamentação, fiscalização e controle. Para prestação dos serviços básicos e complexos de saúde, a CF/88 criou o SUS (art. 198), considerado um dos maiores sistemas públicos de saúde do mundo, sendo o único a garantir assistência integral e completamente gratuita para a população.

Em nome do princípio da eficiência, as ações e serviços de saúde integram uma rede regionalizada e hierarquizada, constituindo o sistema único, que prevê a universalidade e equidade no acesso e, a integralidade das suas ações e participação social na sua gestão. Nesse viés, a Lei Fundamental impõe a descentralização dos serviços de saúde, reconhecendo para tanto, a dimensão territorial do país e não olvidando que as necessidades variam de região para região.

O SUS começa a inovar por ser um sistema nacional - que comporta todos os entes federativos: União, Estados, Municípios e Distrito Federal num único sistema que é descentralizado, com direção única em cada esfera de governo, mas que deve ser organizado sob o formato de rede regionalizada de saúde e com financiamento compartilhado, administrativa e politicamente descentralizado, no sentido de que a Constituição conferiu aos entes federativos o poder-dever de cuidar da saúde; de regular, controlar e fiscalizar a saúde pública e privada (SANTOS, 2010).

É possível perceber que o SUS trouxe inovações na prestação dos serviços de saúde, as quais se refletem no cotidiano do usuário, como a construção de uma concepção mais ampla de saúde, além da promoção de grandes alterações na estrutura organizacional e gerencial do sistema pela política de descentralização dos serviços. Apesar das inovações, ainda é frequente as dificuldades e fragilidades apontadas na implementação do sistema, devido as questões de oposição, corrupção de setores da burocracia e da política, a baixa qualificação dos gestores, assim como a baixa capacidade gerencial dos governos, o surgimento de leis que dificultam a gestão ao estenderem processos burocráticos, que por sua vez reduz a agilidade de implementação das políticas e faz com que os gastos sejam elevados.

Tais dificuldades se refletem nas relações entre os serviços e usuários, o que torna possível realizar estudos que versem sobre a questão da satisfação dos usuários, tendo em vista que a difusão da concepção de administração pública voltada para a qualidade tem dado aos usuários um lugar importante na avaliação dos serviços públicos prestados. Ademais, cabe reforçar, com base nas concepções de Moimaz et al. (2010), que a avaliação do nível de satisfação dos usuários em relação as atividades desenvolvidas pelo sistema de saúde é considerado um indicador relevante para o planejamento das ações da Administração Pública, buscando alcançar a qualidade no serviço prestado, bem como maximizar a adequação em relação a sua 
utilização.

A Administração Pública, por sua vez, é caracterizada, segundo Bobbio et al. (1998), com base na união de atividades, direcionadas à execução de tarefas consideradas de interesse público ou comum, em uma coletividade ou organização estatal, ou seja, a administração pública é compreendida como a atividade de gerenciar o público, por meio de ações de fomento, polícia administrativa e serviços públicos, e ainda pode-se acrescer, em alguns casos, a regulação e a intervenção.

Para que ocorra o exercício dessas atividades e ações, o Estado é composto pela administração direta que desempenha as atividades administrativas de forma centralizada pelas entidades estatais do sistema federativo (União, Estado, Distrito Federal e Municípios); e pela administração indireta que exerce a função administrativa de forma descentralizada, composta por autarquias, empresas públicas, sociedade de economia mista e fundações públicas (art. 4ํ, do Decreto-Lei no 200/67).

No exercício dos serviços públicos, os órgãos e entidades devem obedecer aos princípios constitucionais que regem a Administração Pública, previstos no art. 37, caput, CF/88: princípios da legalidade, impessoalidade, moralidade, publicidade e eficiência. Os estabelecimentos de saúde, na prestação de seus serviços, portanto, devem obediência aos princípios supramencionados. Dentro da perspectiva do presente trabalho, interessante é enforcar-se o princípio da eficiência.

Eficiência deve ser a palavra-chave para hospitais e congêneres atingirem a excelência no atendimento à população, seja uma instituição pública ou privada. Uma gestão eficiente, além de reduzir a possibilidade de corrupção, fornece como efeito colateral benéfico importantes informações que poderão ser utilizadas, inclusive, para a produção de políticas públicas de saúde, trazendo benefícios reais à população (AZEVEDO et al., 2011).

A eficiência relaciona-se com os conceitos como eficácia, resultado, controle, avaliação e cumprimento de metas, posto o direcionamento e feedback desses conceitos centrar-se na satisfação dos usuários-cidadãos dos serviços públicos dispostos pelo Município. Assim, a satisfação, segundo Ferreira (2000), seria o "1. ato ou efeito de satisfazer (-se), 2. Prazer, alegria", onde satisfazer tem relação direta com "realizar, desempenhar, agradar, contentar, corresponder ao que se deseja", e o fim de uma organização e do usuário é a busca da satisfação dos serviços prestados e utilizados.

Os resultados do estudo de Moimaz et al. (2010) revelaram a qualidade do atendimento aos usuários como um importante constructo, uma vez que determina o nível de satisfação dos consumidores, reforçando a necessidade de maximizar a qualificação do serviço prestado, com base na observação de aspectos que dizem respeito a agilidade, responsividade e cortesia..

Frente ao exposto, Kotler (2001) aponta os princípios da qualidade de serviços, a saber: o acesso, a comunicação, a competência dos seus funcionários, a credibilidade da empresa, a confiança nos serviços prestados, a receptividade, a segurança nos serviços, a tangibilidade, a compreensão e o conhecimento do cliente. Vale salientar que o agrupamento de todos os elementos elencados pelo referido autor influenciam diretamente na satisfação dos usuários, já que a satisfação está diretamente ligada às expectativas criadas pelos usuários, assim o grau de satisfação dependerá de como as expectativas foram atendidas:

A satisfação, propiciada por um produto, serviço ou sentimento é função direta do desempenho percebido e das expectativas. Se o desempenho ficar distante das expectativas, o cliente ficará insatisfeito. Se atender às suas expectativas, ficará satisfeito. 
Se exceder às expectativas, ficará altamente satisfeito ou encantado (KUAZAQUI, 2000).

É possível perceber que, no cenário atual, os clientes estão mais exigentes, o que determina das organizações uma maior atenção, estudo e (re) avaliação das práticas de atendimento dos seus servidores/colaboradores/funcionários, de modo que o serviço prestado satisfaça seus clientes/usuários, pois a forma como o mesmo é desempenhado influencia a percepção dos consumidores e a experiência que vivenciam junto à organização, podendo avaliar tal relação por meio de um feedback positivo, caso suas demandas tenham sido atendidas de forma satisfatória, ou através de um retorno negativo, caso sintam-se insatisfeitos e lesados (FERREIRA et al., 2000).

Particularmente nos serviços de saúde, Donabedian (1980) entende qualidade sob três dimensões: técnica, interpessoal e ambiental. A técnica se refere à aplicação atualizada dos conhecimentos científicos na solução do problema do paciente; a interpessoal compreende à relação entre o prestador do serviço e o paciente; e a ambiental diz respeito às comodidades, como conforto e bem-estar oferecidos ao paciente.

[...] a avaliação do ponto de vista dos usuários deve ser feita, sobretudo, por meio da categoria aceitabilidade, que se refere à conformidade dos serviços oferecidos em relação às aspirações dos pacientes e seus familiares. A dimensão da aceitabilidade comporta as principais variáveis através das quais os pacientes podem influir na definição e avaliação da qualidade dos serviços de saúde. Variáveis como relações médico-paciente, condições de acessibilidade ao serviço, dependências e instalações, preferências do paciente em relação aos efeitos e custos do tratamento, bem como tudo aquilo que o paciente considera justo ou equânime (DONABEDIAN, 1984 citado por VAITSMAN et al., 2005).

Assim, a importância de se avaliar a satisfação dos usuários de saúde está na própria avaliação do desempenho do serviço público e da saúde pública do país. Os resultados podem servir de diretrizes para se buscar uma solução dos problemas existentes no sistema e no serviço público de saúde, constituindo-se, principalmente, de um parâmetro para que as organizações públicas busquem melhorar os serviços de saúde, com atendimento de forma digna, integral e universal, centrado na satisfação dos seus usuários.

\section{METODOLOGIA}

O tipo de pesquisa é caracterizado no método de abordagem como uma pesquisa qualitativa, com fins descritivos, cujos dados foram obtidos por meio de questionários aplicados aos usuários do centro de saúde. Para tanto, utilizou-se também a pesquisa survey que tem como propósito a obtenção de dados ou informações sobre características, ações ou opiniões de um determinado grupo de pessoas, indicada como representante de uma população-alvo, feita por meio de um instrumento de pesquisa que normalmente é um questionário (PINSONNEAUT et al., 1993).

A classificação metodológica da pesquisa partiu da taxionomia utilizada por Vergara (2011), nos aspectos: quanto aos fins e quantos aos meios. Quanto aos fins consistiu em caráter exploratório, por proporcionar maior familiaridade com o problema, a fim de torná-lo mais explícito. É pesquisa de caráter descritiva por descrever as características de uma população, de um fenômeno ou de uma experiência. Quanto aos meios, caracterizou-se como de campo, por permitir observar um determinado local e/ou situação e por exigir técnicas de coleta de dados que sejam apropriadas à natureza do tema e, ainda, a própria definição das técnicas que serão empregadas para registro e análise (VERGARA, 2011). 
Os sujeitos da pesquisa foram os usuários que estavam utilizando os serviços de um centro de saúde que integraliza a rede do SUS, localizado em um dos municípios da Microrregião de Cajazeiras, pertencente Mesorregião do Sertão do Estado da Paraíba. A microrregião foi instituída pela Lei Complementar no 106, de 8 de junho de 2012 (Publicada no Diário Oficial da Paraíba 9/06/2012), é composta por 15 (quinze) municípios, possuindo uma área $3.405 \mathrm{~km}^{2}$, Densidade demográfica de 52,1 hab./km² e população de 177393 mil habitantes vivendo na microrregião (CIDADE BRASIL, 2021).

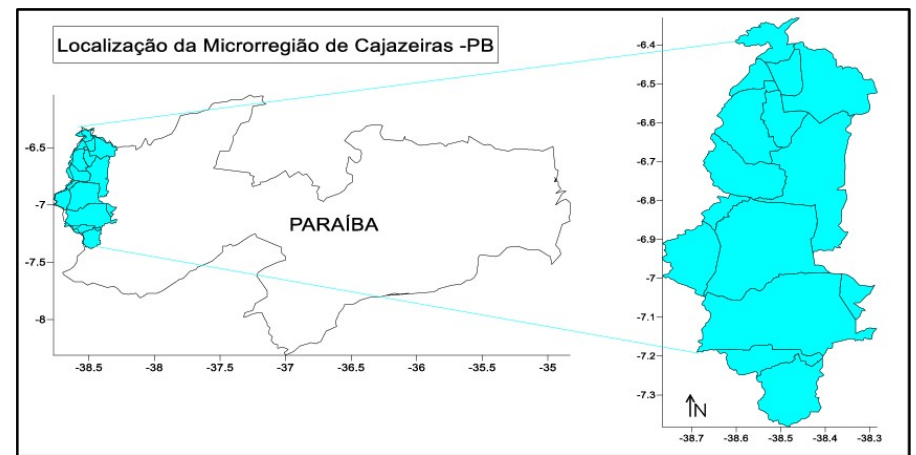

Figura 1: Localização da Microrregião de Cajazeiras-PB. Fonte: LIMA et al. (2015)

A coleta de dados foi realizada por meio de um questionário aplicado aos usuários dos serviços públicos do centro de saúde. A aplicação ocorreu em outubro de 2015, em horário de atendimento, de forma presencial, na entrada do estabelecimento. Foram aplicados 50 (cinquenta) questionários com os usuários que estavam utilizando os serviços, cuja amostra é caracterizada como não-probabilística e por acessibilidade.

Como instrumento de coleta de dados adotou-se o questionário, pois é um meio útil e eficaz para recolher informação num intervalo de tempo relativamente curto (ARTURO, 2001). É um instrumento que visa obter informações da população em estudo de uma maneira sistemática e ordenada (GARCÍA, 2003). 0 questionário da pesquisa foi elaborado pelos autores, composto por 16 quesitos, com perguntas abertas (subjetivas) e fechadas (objetivas) relativas aos fatores considerados determinantes da qualidade, de acordo com Assada (2001): tangibilidade, confiabilidade, pronto atendimento, competência, empatia, credibilidade, segurança, acessibilidade, comunicação e compreensão das necessidades dos clientes.

O tratamento e análise dos dados obtidos com as respostas do questionário se deram da seguinte forma: os quesitos objetivos (fechados) foram analisados por meio do programa Excel (Microsoft Corp., EUA), e os resultados obtidos foram demonstrados por meio de dados gráficos e tabelas (numéricos e/ou percentuais); os quesitos subjetivos (abertos) foram analisados por meio do método da Técnica Interpretativa, utilizando-se da observação e interpretação das respostas obtidas dos sujeitos pesquisados, tendo como base o arcabouço teórico da presente pesquisa, o que possibilitou, ainda, um conjunto de reflexões sobre a temática abordada.

\section{RESULTADOS E DISCUSSÃO}

O levantamento e captação de dados pelos questionários estão relacionados aos indicadores de investigação como: variáveis nominais e gêneros, grau de escolarização, renda e ocupações do usuário, 
acesso e utilização dos serviços, nível de satisfação quanto ao atendimento dos funcionários, instalações, e com os serviços prestados pelo centro de saúde, além de apontar motivações de satisfação e possíveis sugestões para solução de problemas detectados

O perfil dos usuários entrevistados que fizeram parte do objeto de análise da pesquisa, no que tange as variáveis: idade, gênero, nível de escolaridade, origem, ocupação, renda e estrutura familiar, podem ser verificados nas tabelas e gráficos a seguir:

Tabela 1: Perfil dos usuários entrevistados.

\begin{tabular}{|c|c|c|c|}
\hline & Variáveis & Indicadores & $\%$ \\
\hline \multirow[t]{2}{*}{1} & Gênero & Feminino & 62 \\
\hline & & Masculino & 38 \\
\hline \multirow[t]{4}{*}{2} & Idade & De 18 a 25 anos & 32 \\
\hline & & De 26 a 35 anos & 18 \\
\hline & & De 36 a 59 anos & 32 \\
\hline & & Acima de 60 anos & 18 \\
\hline \multirow[t]{4}{*}{3} & Escolaridade & Analfabeto & 22 \\
\hline & & Fundamental & 18 \\
\hline & & Médio & 36 \\
\hline & & Superior & 24 \\
\hline \multirow[t]{3}{*}{4} & Origem dos usuários & Município do centro de saúde & 82 \\
\hline & & Outros municípios da microrregião & 16 \\
\hline & & Municípios de outro Estado & 2 \\
\hline \multirow[t]{4}{*}{5} & Renda mensal & Menos de 1 (um) salário & 25 \\
\hline & & 1 (um) Salário & 53 \\
\hline & & De 1,5 a 2 salários & 18 \\
\hline & & De 3 a 4 salários & 4 \\
\hline \multirow[t]{4}{*}{6} & Composição familiar & 1 (uma) pessoa & 2 \\
\hline & & 2 (duas) a 3 (três) pessoas & 42 \\
\hline & & 4 (quatro) a 5 (cinco) pessoas & 34 \\
\hline & & 6 (seis) ou mais & 22 \\
\hline
\end{tabular}

Quanto ao gênero (Gráfico 1), observa-se uma predominância do feminino (62\%). A maioria dos usuários entrevistados possuía entre 18 a 25 e 36 a 59 anos, ambos com 32\%. Dos usuários entrevistados, $22 \%$ são analfabetos, $18 \%$ possuem o nível fundamental e $36 \%$, a maioria, possui o nível médio.

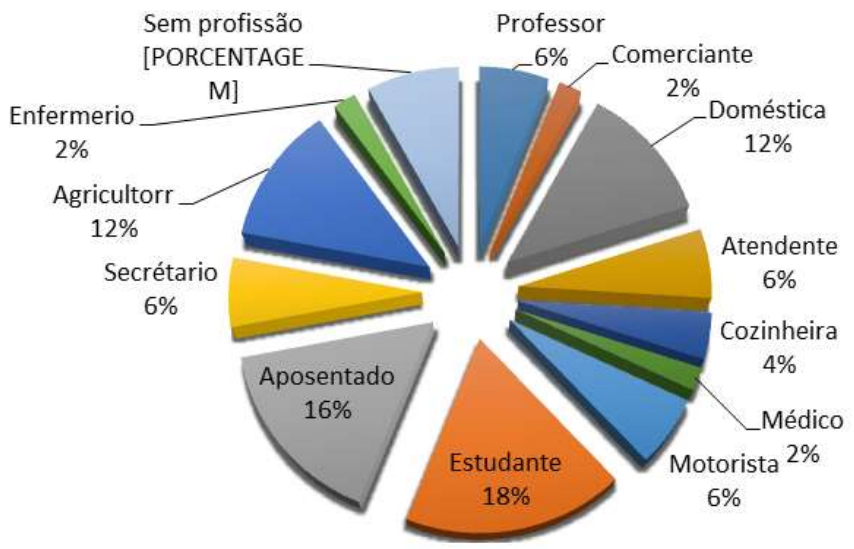

Gráfico 1: Ocupação profissional dos usuários

O nível de instrução dos entrevistados reflete a situação social da família. Dominam as ocupações que não exigem mão-de-obra qualificada para o desempenho (Gráfico 1). Com isso, os salários aferidos por esse segmento são baixos, dada a elevada oferta desse tipo de ocupação. Com renda familiar média abaixo de três salários mínimos, uma parcela significativa dessas pessoas e suas famílias vivem com um ou menos de um salário mínimo. 
Nos gráficos a seguir, tem-se a representação das respostas dos entrevistados, com relação à utilização dos serviços, à frequência, à avaliação de atendimento dos funcionários, o comparativo entre qualidade do atendimento e a resolução de problema, o acesso aos serviços públicos de saúde pelo os usuários e às instalações físicas do centro de saúde.

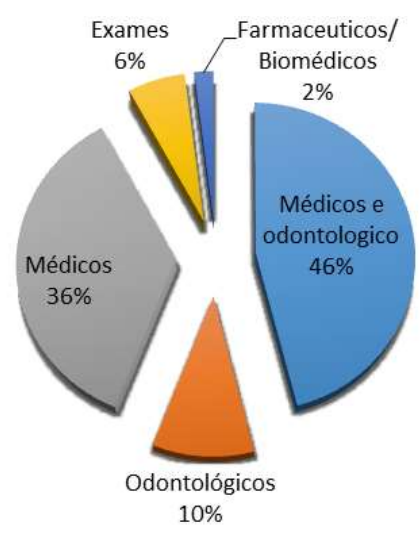

Gráfico 2: Serviços utilizados.

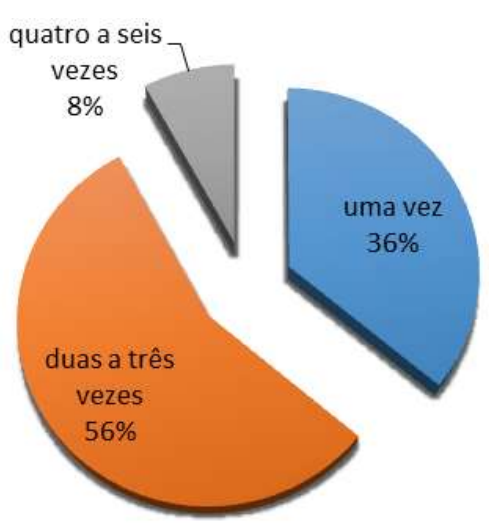

Gráfico 3: Utilização dos serviços por mês.

Quanto ao número de vezes que o usuário utiliza os serviços do Centro de Saúde, durante o mês, a sua maioria informou que utilizam de 2 a 3 vezes (56\%), conforme descrito no Gráfico 3. A qualidade dos serviços de saúde é medida pela capacidade de resolver os problemas de saúde dos clientes. As respostas dos usuários sobre a qualidade dos serviços prestados foram agregadas em três categorias: o serviço atendeu bem e resolveu o problema; o serviço atendeu bem, mas não resolveu o problema; e o serviço atendeu mal. Essas categorias incorporam o ponto de vista dos clientes sobre o atendimento e sua resolutividade.

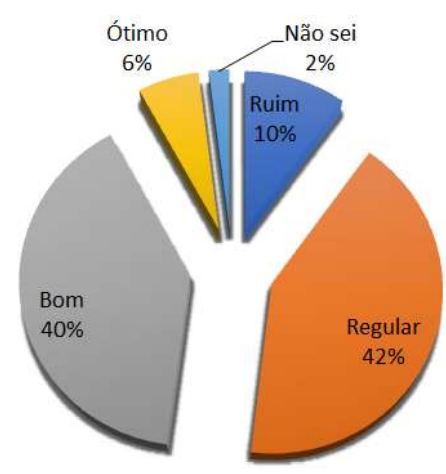

Gráfico 4: Avaliação do usuário do atendimento pelos funcionários

Com relação à variável nível de satisfação dos usuários com o atendimento dos funcionários, verifica-se que a maioria dos entrevistados considera o atendimento Regular (42\%), seguidos de uma parte que consideram o atendimento Bom (40\%), e outra parte avaliaram o atendimento Ruim (10\%). 0 acesso aos serviços de saúde é um componente da aceitabilidade, podendo ser medido quanto aos impedimentos físicos e financeiros e ao próprio serviço prestado: a facilidade em conseguir consulta médica e internação, a proximidade da residência ou local de origem e os gastos para se ter acesso aos serviços.

Ao serem questionados se ao utilizarem alguns dos serviços do centro de saúde, no que referia a qualidade dos serviços de atendimento e a resolução de seu problema, a maioria (54\%) respondeu que os 
serviços prestados pelo estabelecimento de saúde atenderam bem ao usuário, e foi resolvido o seu problema.

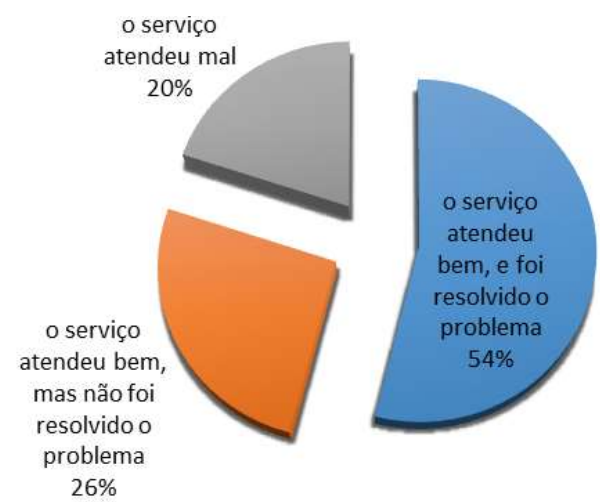

Gráfico 5: Qualidade dos serviços e a resolução dos problemas.

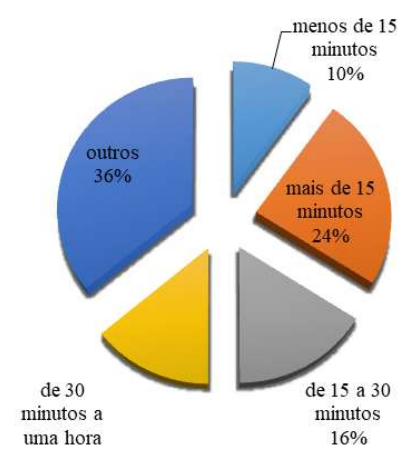

Gráfico 6: Acesso ao Centro de saúde.

Em relação à proximidade, os usuários entrevistados são na quase totalidade, oriundos de locais não próximos ao centro de saúde, embora a maioria (82\%) dos usuários entrevistados residam no próprio município do estabelecimento de saúde. O tempo gasto para esses usuários locomover-se até a unidade de saúde é mais de 15 minutos.

Quanto às instalações físicas do centro de saúde, a maioria (42\%) dos usuários consideraram regular, seguidos de $38 \%$ que consideraram boa, somente $4 \%$ não souberam avaliar ou não quiseram. $A$ satisfação do usuário é a meta do processo de qualidade: as expectativas e necessidades dos usuários devem ser satisfeitas. Por isso, a produção dos serviços de saúde resulta da interação entre usuário e prestador. A qualidade valoriza essa relação e o usuário deixa de ser considerado objeto para assumir a posição de sujeito. No Gráfico 8, a seguir, têm-se a representação gráfica do nível de satisfação dos usuários do centro de saúde, com os serviços prestados.

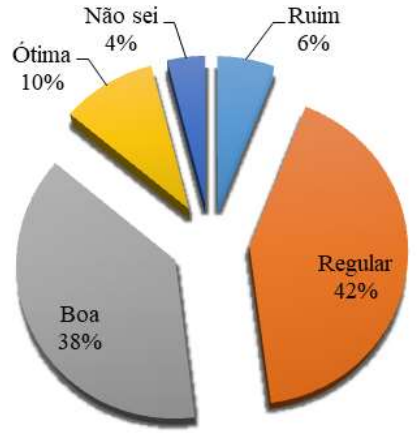

Gráfico 7: Avaliação do usuário das instalações físicas do Centro de Saúde.

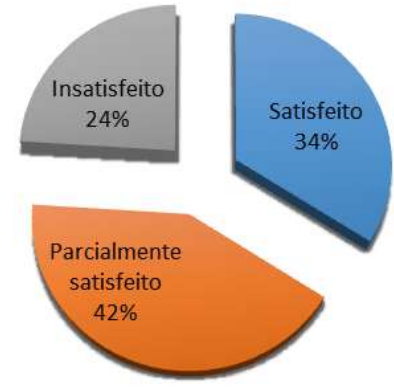

Gráfico 8: Avaliação do nível de satisfação do usuário com serviços.

Com relação à variável nível de satisfação dos usuários dos serviços do centro de saúde, consultando-se a distribuição de frequência das respostas dos usuários entrevistados, representados pelo gráfico 8, verifica-se que: Adota-se nesse gráfico a escala de satisfação entre: Satisfeito, Parcialmente satisfeito e Insatisfeito; Dos usuários entrevistados, 34\% consideraram-se satisfeitos com os serviços prestados pelo centro de saúde; Porém, a maioria dos usuários (42\%) considerou-se parcialmente 
satisfeitos com os serviços de saúde prestados; e Já os usuários que se consideraram como insatisfeitos com os serviços saúde prestados pelo referido Centro, foram $24 \%$.

Após apresentar alguns dados que verificam o nível de satisfação do usuário, é interessante observar os motivos da satisfação ou da insatisfação com os serviços prestados. Os motivos atribuídos à satisfação com o atendimento referem-se, principalmente, ao bom atendimento, o fato de serem bem atendidos, e alguns destacaram que, mesmo com a demora, foram atendidos. Entretanto, o atendimento médico constitui o elemento principal da satisfação com os serviços.

No que tange aos usuários parcialmente satisfeitos, o motivo alegado é a demora no atendimento, a negligência dos funcionários, a falta de médico e aparelhos que não funcionam. Aqui se deve observar o discurso dos entrevistados sobre o motivo de não estarem totalmente satisfeitos com os serviços: "Atendimento lento, enfermeira e outras funcionárias interrompe consulta para ficar de bate papo com os médicos" (Usuário 22, sic); “Às vezes sou atendido, às vezes venho, espero horas e não há atendimento"; e "esperou horas e o médico ligou dizendo que não vinha" (Usuário 09, sic).

A demora no atendimento é o principal motivo de insatisfação, tal fato é reiterado no discurso dos entrevistados: "Insatisfeito com o atendimento médico, cheguei ao posto de $6 \mathrm{~h}$ da manhã e fui atendido às 11 hs da manhã. $O$ médico chegou às $10 \mathrm{~h}$ e ainda fica de conversinha com os funcionários" (Usuário 44, sic); ou ainda: "Mau atendimento, médicos não são pontuais, e passamos horas e mais horas esperando médicos aqui" (Usuário 33, sic); e outro: "fui mal atendido pelo porteiro e enfermeiro de plantão cheguei com uma pessoa com febre e tinha mais de vinte pessoas na minha frente, e responderam para ele: se quiser ser atendido espere os vinte entrar" (Usuário 17, sic); outro entrevistado também mencionou "não gostei dos atendimentos com as pessoas mais pobres" (Usuário 07, sic).

Quanto às sugestões, os usuários apontam a necessidade de mais profissionais específicos nas áreas médicas, agilidade no atendimento, melhorar a escala para os horários dos médicos, filas mais organizadas, melhora na ética dos funcionários, criação de mais leitos, atendimento igualitário e priorização dos casos de urgência, e médicos chegando no horário certo.

\section{CONCLUSÕES}

A avaliação da qualidade do serviço público de saúde no Centro de Saúde em questão bem como o processo que envolve os usuários mostra que os serviços prestados, segundo a avaliação dos usuários, em sua maioria, estão parcialmente satisfeitos, ou seja, demonstram satisfação em algumas áreas do atendimento, e noutras não. Aqueles que não estão satisfeitos com o atendimento mencionam o tempo de espera e a qualidade do atendimento como determinante da insatisfação. Portanto, em que se pese as dificuldades existentes no sistema local de saúde e na impossibilidade de cobrir toda a demanda, os usuários estão satisfeitos com o atendimento e com sua resolubilidade.

É possível também identificar, por meio de informações colhidas junto aos usuários, os pontos a serem tratados com maior atenção por parte dos gerentes. Concluiu-se ser necessária uma revisão geral nas práticas atualmente adotadas na gestão de pessoas, no quesito atendimento, a fim de motivar os 
funcionários, o que provavelmente poderá resultar em níveis maiores de produtividade, contribuindo, em vista disso, para a satisfação dos usuários.

Dessa forma, é possível refletir que a satisfação dos usuários confirma o que a literatura já vinha produzindo, ou seja, a satisfação está diretamente ligada às expectativas criadas pelos usuários, onde o grau de satisfação dependerá de como as expectativas foram atendidas, e no caso in loco não difere. Por fim, chega-se à conclusão que a descentralização dos serviços públicos de saúde por meio do SUS, confere ao ente municipal a responsabilidade pela prestação do serviço público de saúde, o que o torna um dos responsáveis por garantir aos munícipes o direito à saúde.

\section{REFERÊNCIAS}

ARTURO, R. R.. El Cuestionario. 2001.

AZEVEDO, C. R.; CARVALHO, É.. A saúde dos Hospitais. Revista Jurídica Consulex, v.15, n.348, 2011.

BOBBIO, N.; MATTEUCCI, N.; PASQUINO, G.. Dicionário de política. Brasília: Universidade de Brasília, 1998.

BRASIL. Constituição da República Federativa do Brasil de 1988. Brasília: DOU, 1988.

BRASIL. Lei no. 8.080. Dispões sobre as condições para a promoção, proteção e recuperação da saúde, a organização e o funcionamento dos serviços correspondentes e dá outras providências. Brasília: DOU, 1990.

BRASIL. Decreto-lei no 200. Dispõe sôbre a organização da Administração Federal, estabelece diretrizes para a Reforma Administrativa e dá outras providências. Brasília: DOU, 1967.

IBGE. Instituto Brasileiro de Geografia e Estatística. Cidades e Estados. IBGE, 2021.

DONABEDIAN, A.. Explorations in quality assessment and monitoring: the definition of quality and approaches to its assessment. Health Administration Press, v.1, p.163-1980.

DONABEDIAN, A.. La calidad de la atención médica: definición y métodos de evaluación. 1984.

VAITSMAN, J.; ANDRADE, G. R. B.. Satisfação e responsabilidade: formas de medir a qualidade e a humanização da assistência à saúde. Ciência \& Saúde coletiva, v.10, n.3, p.599-613, 2005.

FERREIRA, A. B. H.. Mini Aurélio Século XXI Escolar: o minidicionário da língua portuguesa. 4 ed. Rio de Janeiro:
Nova fronteira, 2000.

FERREIRA, S.; SGANZERLLA, S.. Conquistando o consumidor: o marketing de relacionamento como vantagem competitiva das empresas. São Paulo: Gente, 2000.

GARCÍA, M. T.. El Cuestionario como instrumento de investigación/Evaluacion. 2003.

JUNQUILHO, G. S.. Teorias da administração pública. 2010.

KOTLER, P.. Administração de Marketing: análise, planejamento, implementação e controle. 10 ed. São Paulo: Atlas, 2001

KUAZAQUI, E.. Marketing turístico e de hospitalidade: fonte de empregabilidade e desenvolvimento para o Brasil. São Paulo: Makron Books, 2000.

LIMA, S. L.; BARBOSA, R. R.; SOUZA, W. G.; RIBEIRO, G. N.; FRANCISCO, P. R. M.. Uso de geotecnologias para o mapeamento temático dos IDHM'S para a microrregião de cajazeiras. 2015

MEIRELLES, H. L.. Direito Administrativo Brasileiro. São Paulo: Malheiros, 2008. MOIMAZ, S. A. S.; MARQUES, J. A. M.; SALIBA, O.; GARBIN, C. A. S.; ZINA, L. G.; SALIBA, N. A.. Satisfação e percepção do usuário do SUS sobre o serviço público de saúde. Physis: Revista de Saúde Coletiva, Rio de Janeiro, v.20, n.4, p.14191440, 2010.

OLIVO, L. C. C.. Direito Administrativo. 2010.

SANTOS, L.. Administração pública e a gestão da saúde. In: SANTOS, N. R.; CARVALHO, P. D.. Gestão Pública e relação público privado na saúde. Rio de Janeiro: Cebes, 2010.

A CBPC - Companhia Brasileira de Produção Científica (CNPJ: 11.221.422/0001-03) detém os direitos materiais desta publicação. Os direitos referem-se à publicação do trabalho em qualquer parte do mundo, incluindo os direitos às renovações, expansões e disseminações da contribuição, bem como outros direitos subsidiários. Todos os trabalhos publicados eletronicamente poderão posteriormente ser publicados em coletâneas impressas sob coordenação da Sustenere Publishing, da Companhia Brasileira de Produção Científica e seus parceiros autorizados. Os (as) autores (as) preservam os direitos autorais, mas não têm permissão para a publicação da contribuição em outro meio, impresso ou digital, em português ou em tradução. 